\title{
Changes in contact patterns shape the dynamics of the COVID-19 outbreak in China
}

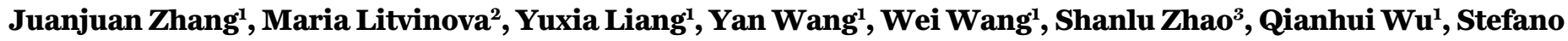 \\ Merler $^{4}$, Cécile Viboud $^{5}$, Alessandro Vespignani ${ }^{6,2}$, Marco Ajelli ${ }^{4 *+}$, Hongjie Yu${ }^{1 * \dagger}$ \\ ${ }^{1}$ School of Public Health, Fudan University, Key Laboratory of Public Health Safety, Ministry of Education, Shanghai, China. ${ }^{2}$ SI Foundation, Turin, Italy. ${ }^{3} \mathrm{Hunan}$ Provincial \\ Center for Disease Control and Prevention, Changsha, China. ${ }^{4}$ Bruno Kessler Foundation, Trento, Italy. ${ }^{5}$ Division of International Epidemiology and Population Studies, \\ Fogarty International Center, National Institutes of Health, Bethesda, MD, USA. ${ }^{6}$ Laboratory for the Modeling of Biological and Socio-technical Systems, Northeastern \\ University, Boston, MA, USA. \\ *These authors contributed equally to this work. †Corresponding author. Email: marco.ajelli@gmail.com (M.A.); yhj@fudan.edu.cn (H.Y.)
}

Intense non-pharmaceutical interventions were put in place in China to stop transmission of the novel coronavirus disease (COVID-19). As transmission intensifies in other countries, the interplay between age, contact patterns, social distancing, susceptibility to infection, and COVID-19 dynamics remains unclear. To answer these questions, we analyze contact surveys data for Wuhan and Shanghai before and during the outbreak and contact tracing information from Hunan Province. Daily contacts were reduced 7-8-fold during the COVID-19 social distancing period, with most interactions restricted to the household. We find that children 0-14 years are less susceptible to SARS-CoV-2 infection than adults 15-64 years of age (odd ratio $0.34,95 \% \mathrm{Cl} 0.24-0.49$ ), while in contrast, individuals over 65 years are more susceptible to infection (odd ratio 1.47, 95\% Cl: 1.12-1.92). Based on these data, we build a transmission model to study the impact of social distancing and school closure on transmission. We find that social distancing alone, as implemented in China during the outbreak, is sufficient to control COVID-19. While proactive school closures cannot interrupt transmission on their own, they can reduce peak incidence by $40-60 \%$ and delay the epidemic.

The novel coronavirus disease 2019 (COVID-19) epidemic caused by SARS-CoV-2 began in Wuhan City, China in December 2019 and quickly spread globally, with 2,063,161 cases reported in 185 countries/regions as of April 16, 2020 (1). A total of 82,692 cases of COVID-19, including 4,632 deaths, have been reported in mainland China, including 50,333 cases in Wuhan City and 628 cases in Shanghai City (2). The epidemic in Wuhan and in the rest of China subsided after implementation of strict containment measures and movement restrictions, with recent cases originating from travel (3). However, key questions remain about the age profile of susceptibility to infection, how social distancing alters agespecific contact patterns, and how these factors interact to affect transmission. These questions are relevant to the choice of control policies for governments and policy makers around the world. In this study, we evaluate changes in mixing patterns linked to social distancing by collecting contact data in the midst of the epidemic in Wuhan and Shanghai. We also estimate age differences in susceptibility to infection based on contact tracing data gathered by the Hunan Provincial Center for Disease Control and Prevention (CDC), China. Based on these empirical data, we develop a mathematical disease transmission model to disentangle how transmission is affected by age differences in the biology of COVID-19 infection and altered mixing patterns due to social distancing.
Additionally, we project the impact of social distancing and school closure on COVID-19 transmission.

To estimate changes in age-mixing patterns associated with COVID-19 interventions, we performed contact surveys in two cities: Wuhan, the epicenter of the outbreak, and Shanghai, one of the largest and most densely populated cities in southeast China. Shanghai experienced extensive importation of COVID-19 cases from Wuhan as well as local transmission (4). The surveys were conducted from February 1, 2020 to February 10, 2020, as transmission of COVID-19 peaked across China and stringent interventions were put in place. Participants in Wuhan were asked to complete a questionnaire describing their contact behavior $(5,6)$ on two different days: i) a regular weekday between December 24, 2019 and December 30, 2019, before the COVID-19 outbreak was officially recognized by the Wuhan Municipal Health Commission (used as baseline); and ii) the day before the interview (outbreak period). Participants in Shanghai were asked to complete the same questionnaire used for Wuhan, but only reported contacts for the outbreak period. For the baseline period in Shanghai, we relied on a survey conducted in 20172018 following the same design (7). In these surveys, a contact was defined as either a two-way conversation involving three or more words in the physical presence of another person, or a direct physical contact (e.g., a handshake). Details are given 
in the supplementary materials (sections 1 and 2).

We analyzed a total of 1,245 contacts reported by 636 study participants in Wuhan, and 1,296 contacts reported by 557 participants in Shanghai. In Wuhan, the average daily number of contacts per participant was significantly reduced from 14.6 for the baseline period (weighted mean contacts by age structure: 14.0) to 2.0 for the outbreak period (weighted mean contacts by age structure: 1.9$)(\mathrm{p}<0.001)$. The reduction in contacts was significant for all stratifications by sex, age group, type of profession, and household size (Table 1). A larger reduction was observed in Shanghai, where the average daily number of contacts declined from 18.8 (weighted mean contacts by age structure: 19.8) to 2.3 (weighted mean contacts by age structure: 2.1). Although an average individual in Shanghai reported more contacts than one in Wuhan on a regular weekday, this difference essentially disappeared during the COVID-19 outbreak period. A similar decrease in the number of contacts was found in the UK during the COVID-19 lockdown period (8).

The typical features of age-mixing patterns $(6,7)$ emerge in Wuhan and Shanghai when we consider the baseline period (Fig. 1, A and D). These features can be illustrated in the form of age-stratified contact matrices (provided as ready-touse tables in the supplementary materials, section 3.6), where each cell represents the average number of contacts that an individual has with other individuals, stratified by age groups. The bottom left corner of the matrix, corresponding to contacts between school-age children, is where the largest number of contacts is recorded. The contribution of contacts in the workplace is visible in the central part of the matrix, while the three diagonals (from bottom left to top right) represent contacts between household members. In contrast, for the outbreak period where strict social distancing policies were in place, much of the above-mentioned features disappears, essentially leaving the sole contribution of household mixing (Fig. 1, B and E). In particular, assortative contacts between school-age individuals are fully removed, as illustrated by differencing baseline and outbreak matrices (Fig. 1, $\mathrm{C}$ and F). Overall, contacts during the outbreak mostly occurred at home with household members $(94.1 \%$ in Wuhan and $78.5 \%$ in Shanghai). Thus, the outbreak contact matrix nearly coincides with the within-household contact matrix in both study sites and the pattern of assortativity by age observed for regular days almost entirely disappears (see supplementary materials, section 3.6). These findings are consistent with trends in within-city mobility data, which indicate an $86.9 \%$ drop in Wuhan and $74.5 \%$ in Shanghai between early January and early February (see supplementary materials, section 4). Such a large decrease in internal mobility is consistent with most of contacts occurring in the household during the outbreak period. Of note, the strict social distancing measures implemented in Wuhan and Shanghai did not entirely zero out contacts in the workplace, as essential workers continued to perform their activities (as observed in our data, see supplementary materials, section 3.5).

The estimated mixing patterns are based on self-reported contacts that can thus be affected by various biases. In particular, reported contacts for the baseline period in Wuhan may be prone to recall bias since contacts were assessed retrospectively. Further, due to retrospective nature of the baseline survey in Wuhan, we were unable to account for the lower number of contacts during weekends. The more complete data from Shanghai did not suffer recall bias and allowed us to weight contacts for weekdays and weekends sensitivity analyses suggest that this has little impact on results (supplementary materials, section 8.3 ). Another possible bias is that survey participants may have felt pressure to minimize reported contacts occurring during the outbreak, given that social distancing was in place and strictly enforced by the government, even if the anonymity and confidentiality of the survey were emphasized. However, results are robust to inflating reported contacts outside of the home several fold, suggesting that these compliance and social acceptability biases linked to the outbreak period do not affect our main findings (supplementary materials, section 8.2). Another caveat is that in parallel to population-level social distancing measures, case-based interventions were implemented and could have affect contacts, including rapid isolation of confirmed and suspected cases, and quarantine of close contacts for 14 days. Only a small portion of the population in the two study sites was affected by contact tracing and quarantine, however, thus having little to no effect on average contact patterns in the general population.

Next, to understand the interplay between social distancing interventions, changes in human mixing patterns, and outbreak dynamics, we need to consider potential age differences in susceptibility to infection. This is currently a topic of debate, as little information on the age profile of asymptomatic cases is available $(9,10)$. To this aim, we analyzed COVID-19 contact tracing information gleaned from detailed epidemiological field investigations conducted by the Hunan CDC (supplementary materials, section 5). Briefly, all close contacts of COVID-19 cases reported in Hunan province were placed under medical observation for 14 days and were tested using real-time RT-PCR. Those who tested positive were considered as SARS-CoV-2 infections. We estimated the odd ratios (OR) for a contact of a certain age group to be infected, relative to a reference age group. We performed generalized linear mixed model regression to account for clustering and potential correlation structure of contacts exposed to the same index case (e.g., in the household). We included age group and gender of a contact, type of contact, and whether the contact traveled to Hubei/Wuhan as regression covariates (see supplementary materials, section 5). We found that 
susceptibility to SARS-CoV2 infection increased with age. Young individuals (aged 0-14 years) had a lower risk of infection than individual aged 15-64 years [OR=0.34 (95\%CI: 0.24$0.49)$, p-value $<0.0001]$. In contrast, older individuals aged 65 years and over had a higher risk of infection than adults 1564 years [OR=1.47 (95\%CI: $1.12-1.92)$, p-value $=0.005]$. These findings are in contrast with a previous study in Shenzhen, where susceptibility to infection did not change with age (9).

Next, we explore how our data can inform control strategies for COVID-19. A key parameter regulating the dynamics of an epidemic is the basic reproduction number $\left(R_{0}\right)$, which corresponds to the average number of secondary cases generated by an index case in a fully susceptible population. We estimated the impact of interventions on $\mathrm{R}_{0}$, relying on our age-specific estimates of susceptibility to infection and contact patterns before and during interventions. We used the next generation matrix approach to quantify changes in $R_{0}$ (11) (supplementary materials, section 6). Additionally, to illustrate the impact of age-mixing patterns on the dynamics of the epidemic, we developed a simple SIR model of SARSCoV-2 transmission (supplementary materials, section 6). In the model, the population is divided into three epidemiological categories: susceptible, infectious, and removed (either recovered or deceased individuals), stratified by 14 age groups. Susceptible individuals can become infectious after contact with an infectious individual according to the estimated age-specific susceptibility to infection. The rate at which contacts occur is determined by the estimated mixing patterns of each age group. The mean time interval between two consecutive generations of cases was taken to be 5.1 days, assuming it aligns with the mean of the serial interval reported by Zhang et al. (3).

In the early phases of COVID-19 spread in Wuhan, before interventions were put in place, $\mathrm{R}_{0}$ values were estimated to range between 2.0 and 3.5 (12-18). In this analysis, we extended this range from 1 to 4 for the baseline period (i.e., before interventions). We find that the considerable changes of mixing patterns observed in Wuhan and Shanghai during the social distancing period led to a drastic decrease in $\mathrm{R}_{0}$ (Fig. 2 ). When we consider contact matrices representing the outbreak period, keeping the same baseline disease transmissibility as in the pre-intervention period, the reproductive number drops well below the epidemic threshold in Wuhan (Fig. 2A) and Shanghai (Fig. 2B). This finding is robust to relaxing assumptions about age differences in susceptibility to infection; the epidemic is still well controlled if SARS-CoV-2 infection is assumed to be equally likely in all age groups (Fig. 2, A and B). We also performed sensitivity analyses regarding possible recall and compliance biases of self-reported contacts as well as the definition of contact (i.e., considering only contacts lasting more than $5 \mathrm{~min}$ ). The results are consistent with those reported here (see supplementary materials, section 8).

In an uncontrolled epidemic (without intervention measures, travel restrictions, or spontaneous behavioral responses of the population), and for $\mathrm{R}_{0}$ in the range $2-3$, we estimate the mean infection attack rate to be in the range $53 \%-92 \%$ after a year of SARS-CoV-2 circulation, with slight variation between Wuhan (Fig. 2C) and Shanghai (Fig. 2D). These estimates should be considered as an upper bound of the infection attack rate as they are based on a compartmental model that does not account for high clustering of contacts (e.g., repeated contacts among household members). If we consider a scenario where social distancing measures are implemented early on, as the new virus emerges, the estimated $\mathrm{R}_{0}$ remains under the epidemic threshold and thus the epidemic cannot take off in either location. Furthermore, we estimate that the magnitude of interventions implemented in Wuhan and Shanghai would have been enough to block transmission for an $\mathrm{R}_{0}$ before the interventions up to $\sim 6$ in Wuhan and 7.8 in Shanghai.

Next, we use the model to estimate the impact of preemptive mass school closure. We considered two different contact pattern scenarios, based on data from Shanghai: contacts estimated during vacations period (7) and contacts estimated during regular weekdays, after all contacts occurring in school settings have been removed (7). Both scenarios represent a simplification of a school closure strategy. In fact, school closures in response to the COVID-19 pandemic in China have entailed interruption of all educational on-site services. However, mixing patterns measured during school vacations indicate that a fraction of children still attend additional educational activities as typical in Chinese cities. On the other hand, when removing all contacts in the school setting, we do not consider potential trickle down effects on the mixing patterns of other age groups; for instance, parents may need to leave work to take care of school-age children. Our modeling approach indicates that limiting contact patterns to those observed during vacations would interrupt transmission for baseline $\mathrm{R}_{0}$ up to 1.5 (Fig. 3, A and C). Removing all school contacts would do the same for baseline $\mathrm{R}_{0}$ up to 1.2. If we apply these interventions to a COVID-19 scenario, assuming a baseline $R_{0}$ of $2-3.5$, we can achieve a noticeable decrease in infection attack rate and peak incidence, and a delay in the epidemic, but transmission is not interrupted (Fig. 3, B and D). For instance, for baseline $\mathrm{R}_{0}=2.5$ and assuming a vacation mixing pattern, the mean peak daily incidence is reduced by about $64 \%$. In the corresponding scenario where school contacts are removed, we estimate a reduction of about $42 \%$. Overall, school-based closure policies are not sufficient to entirely prevent a COVID-19 outbreak, but they can impact disease dynamics, and hence hospital surge capacity. It is important to stress that individuals aged 5-19 years in Shanghai represent $9.5 \%$ of the population (19), 
markedly lower than the mean in China $[16.8 \%$ (19)] and other countries [including Western countries; e.g., 19.7\% in the US (20)].

The results of this study should be considered in the light of the following limitations. In our simulation model, we estimated the effect of social distancing alone; combining social distancing with other interventions would have a synergistic effect to even further reduce transmission. It is likely that population wide social distancing, case-based strategies, and decontamination efforts, all contributed to achieve control in Wuhan and Shanghai, and their effect is difficult to separate out in retrospective observational studies. Our estimates of age differences in susceptibility to infection are based on active testing of 7,375 contacts of 136 confirmed index cases. These data suffer from the usual difficulties inherent to the reconstruction of epidemiological links and detection of index cases. Contact data are useful but seroepidemiology studies will be essential to fully resolve population susceptibility profiles to SARS-CoV-2 infection and disease. While the age patterns of contacts were similar in the two study locations during the COVID-19 outbreak period, these patterns may not be fully representative of other locations in China and abroad, where social distancing measures may differ. As reliable estimates of the contribution of asymptomatic SARSCoV-2 infections to transmission are still lacking, we did not explicitly model differences between symptomatic and asymptomatic individuals. We considered a serial interval of 5.1 days (3), based on a prior estimate from China, at a time when case-based and contact tracing interventions measures were in place, which tends to shorten the interval between successive cases. However, this choice does not affect the estimated changes in reproduction number between the baseline and outbreak periods. Modeling results may underestimate the effect of social distancing interventions as our results concentrate on number of contacts and ignore the type of social interactions (e.g., increased distance between individuals while in contact, or use of face mask), which may have changed due increased awareness of the population (21, 22). Finally, it is worth noting that our school closure simulations are not meant to formulate a full intervention strategy, which would require identification of epidemic triggers to initiate closures and evaluation of different durations of intervention (6). Nonetheless, our modeling exercise provides an indication of the possible impact of a nation-wide preemptive strategy on the infection attack rate and peak incidence. To generalize these findings to other contexts, location-specific age-mixing patterns and population structures should be considered. Most importantly perhaps, strict lockdown strategies of the kind implemented in Wuhan, Shanghai, and in other regions of the world are extremely disruptive economically and mentally, and more targeted approaches to block transmission are preferable in the long run. We do not necessarily endorse blunt lockdown policies here; merely we describe their impact on COVID-19 transmission based on the Chinese experience.

Our study provides evidence that the interventions put in place in Wuhan and Shanghai, and the resulting changes in human behavior, drastically decreased daily contacts, essentially reducing them to household interactions. This leads to a dramatic reduction of SARS-CoV-2 transmission. As lockdown measures are put in place in other locations, human mixing patterns in the outbreak period could be captured by data on within-household contacts, which are available for several countries around the world (5-7, 23-25). Moving forward, it will be particularly important to design targeted strategies for long-term control of COVID-19, including school- and work-based control strategies, along with large scale testing and contact tracing (26-28). Research should concentrate on refining age-specific estimates of susceptibility to infection, disease, and infectiousness, which are instrumental to evaluating the impact of these strategies.

\section{REFERENCES AND NOTES}

1. Johns Hopkins University, COVID-19 Dashboard (2020): https://coronavirus.jhu.edu/map.html [accessed 16 April 2020].

2. Chinese Center for Disease Control and Prevention, Update on COVID-19 as of 24:00 on April 16, 2020 (2020); http://2019ncov.chinacdc.cn/2019-nCoV/ [accessed 17 April 2020].

3. J. Zhang, M. Litvinova, W. Wang, Y. Wang, X. Deng, X. Chen, M. Li, W. Zheng, L. Yi, X. Chen, Q. Wu, Y. Liang, X. Wang, J. Yang, K. Sun, I. M. Longini Jr., M. E. Halloran, P. Wu, B. J. Cowling, S. Merler, C. Viboud, A. Vespignani, M. Ajelli, H. Yu, Evolving epidemiology and transmission dynamics of coronavirus disease 2019 outside Hubei province, China: A descriptive and modelling study. Lancet Infect. Dis. S1473-3099(20)30230-9 (2020). doi:10.1016/S1473-3099(20)30230-9 Medline

4. The Novel Coronavirus Pneumonia Emergency Response Epidemiology Team, The epidemiological characteristics of an outbreak of 2019 novel coronavirus diseases (COVID-19) - China, 2020. China CDC Weekly 2, 113-122 (2020).

5. J. Mossong, N. Hens, M. Jit, P. Beutels, K. Auranen, R. Mikolajczyk, M. Massari, S. Salmaso, G. S. Tomba, J. Wallinga, J. Heijne, M. Sadkowska-Todys, M. Rosinska, W. J. Edmunds, Social contacts and mixing patterns relevant to the spread of infectious diseases. PLOS Med. 5, e74 (2008) doi:10.1371/journal.pmed.0050074 Medline

6. M. Litvinova, Q. H. Liu, E. S. Kulikov, M. Ajelli, Reactive school closure weakens the network of social interactions and reduces the spread of influenza. Proc. Natl. Acad. Sci. U.S.A. 116, 13174-13181 (2019). doi:10.1073/pnas.1821298116 Medline

7. J. Zhang, P. Klepac, J. M. Read, A. Rosello, X. Wang, S. Lai, M. Li, Y. Song, Q. Wei, H. Jiang, J. Yang, H. Lynn, S. Flasche, M. Jit, H. Yu, Patterns of human social contact and contact with animals in Shanghai, China. Sci. Rep. 9, 15141 (2019). doi:10.1038/s41598-019-51609-8 Medline

8. C. I. Jarvis, K. Van Zandvoort, A. Gimma, K. Prem, P. Klepac, G. J. Rubin, W. J. Edmunds; CMMID COVID-19 working group, Quantifying the impact of physical distance measures on the transmission of COVID-19 in the UK. medRxiv 2020.03.31.20049023 [Preprint]. 3 April 2020 https://doi.org/10.1101/2020.03.31.20049023.

9. Q. Bi, Y. Wu, S. Mei, C. Ye, X. Zou, Z. Zhang, X. Liu, L. Wei, S. A. Truelove, T. Zhang, W. Gao, C. Cheng, X. Tang, X. Wu, Y. Wu, B. Sun, S. Huang, Y. Sun, J. Zhang, T. Ma, J. Lessler, T. Feng, Epidemiology and Transmission of COVID-19 in Shenzhen China: Analysis of 391 cases and 1,286 of their close contacts. medRxiv 2020.03.03.20028423 [Preprint]. 27 March 2020 https://doi.org/10.1101/2020.03.03.20028423.

10. K. Mizumoto, K. Kagaya, A. Zarebski, G. Chowell, Estimating the asymptomatic proportion of 2019 novel coronavirus onboard the Princess Cruises ship. medRxiv 2020.02.20.20025866 [Preprint]. 6 March 2020. 
https://doi.org/10.1101/2020.02.20.20025866

11. O. Diekmann, J. A. P. Heesterbeek, J. A. J. Metz, On the definition and the computation of the basic reproduction ratio $R_{0}$ in models for infectious diseases in heterogeneous populations. J. Math. Biol. 28, 365-382 (1990). doi:10.1007/BF00178324 Medline

12. J. T. Wu, K. Leung, G. M. Leung, Nowcasting and forecasting the potential domestic and international spread of the 2019-nCoV outbreak originating in Wuhan, China: A modelling study. Lancet 395, 689-697 (2020). doi:10.1016/S01406736(20)30260-9 Medline

13. J. M. Read, J. R. Bridgen, D. A. Cummings, A. Ho, C. P. Jewell, Novel coronavirus 2019-nCoV: early estimation of epidemiological parameters and epidemic predictions. medRxiv 2020.01.23.20018549 [Preprint]. 28 January 2020. https://doi.org/10.1101/2020.01.23.20018549.

14. Q. Li, X. Guan, P. Wu, X. Wang, L. Zhou, Y. Tong, R. Ren, K. S. M. Leung, E. H. Y. Lau, J. Y. Wong, X. Xing, N. Xiang, Y. Wu, C. Li, Q. Chen, D. Li, T. Liu, J. Zhao, M. Liu, W. Tu, C. Chen, L. Jin, R. Yang, Q. Wang, S. Zhou, R. Wang, H. Liu, Y. Luo, Y. Liu, G. Shao, H. Li, Z. Tao, Y. Yang, Z. Deng, B. Liu, Z. Ma, Y. Zhang, G. Shi, T. T. Y. Lam, J. T. Wu, G. F. Gao, B. J. Cowling, B. Yang, G. M. Leung, Z. Feng, Early transmission dynamics in Wuhan, China, of novel coronavirus-infected pneumonia. N. Engl. J. Med. 382, 1199-1207 (2020). doi:10.1056/NEJMoa2001316 Medline

15. S. Abbott, J. Hellewell, J. Munday, S. Funk; CMMID nCoV working group, The transmissibility of novel coronavirus in the early stages of the 2019-20 outbreak in Wuhan: Exploring initial point-source exposure sizes and durations using scenario analysis. Wellcome Open Res. 5, 17 (2020). doi:10.12688/wellcomeopenres.15718.1 Medline

16. M. Chinazzi, J. T. Davis, M. Ajelli, C. Gioannini, M. Litvinova, S. Merler, A. Pastore Y Piontti, K. Mu, L. Rossi, K. Sun, C. Viboud, X. Xiong, H. Yu, M. E. Halloran, I. M. Longini Jr., A. Vespignani, The effect of travel restrictions on the spread of the 2019 novel coronavirus (COVID-19) outbreak. Science 368, 395-400 (2020). doi:10.1126/science.aba9757 Medline

17. I. Natsuko, A. Cori, I. Dorigatti, M. Baguelin, C. A. Donnelly, S. Riley, N. M. Ferguson, "Report 3: Transmissibility of 2019-nCoV" (Imperial College London, 2020); www.imperial.ac.uk/media/imperial-college/medicine/sph/ide/gidafellowships/Imperial-College-COVID19-transmissibility-25-01-2020.pdf.

18. World Health Organization, "Report of the WHO-China Joint mission on coronavirus disease 2019 (COVID-19)," (WHO, 2020); www.who.int/docs/default-source/coronaviruse/who-china-joint-mission-oncovid-19-final-report.pdf [accessed 11 March 2020].

19. National Bureau of Statistics, China census data (2020); www.stats.gov.cn/ [accessed 1 March 2020].

20. United Nations, World population prospects 2019 (2019); https://population.un.org/wpp/Download/Standard/Population/ [accessed 15 April 2019].

21. B. J. Cowling, S. T. Ali, T. W. Y. Ng, T. K. Tsang, J. C. M. Li, M. W. Fong, Q. Liao, M. Y. W. Kwan, S. L. Lee, S. S. Chiu, J. T. Wu, P. Wu, G. M. Leung, Impact assessment of non-pharmaceutical interventions against COVID-19 and influenza in Hong Kong: an observational study. medRxiv 2020.03.12.20034660 [Preprint]. 16 March 2020. https://doi.org/10.1101/2020.03.12.20034660.

22. M. Qian, Q. Wu, P. Wu, Z. Hou, Y. Liang, B. J. Cowling, H. Yu, Psychological responses, behavioral changes and public perceptions during the early phase of the COVID-19 outbreak in China: a population based cross-sectional survey. medRxiv 2020.02.18.20024448 [Preprint]. 20 February 2020; https://doi.org/10.1101/2020.02.18.20024448.

23. T. Hoang, P. Coletti, A. Melegaro, J. Wallinga, C. G. Grijalva, J. W. Edmunds, P. Beutels, N. Hens, A systematic review of social contact surveys to inform transmission models of close-contact infections. Epidemiology 30, 723-736 (2019). doi:10.1097/EDE.0000000000001047 Medline

24. D. Mistry, M. Litvinova, A. Pastore y Piontti, M. Chinazzi, L. Fumanelli, M. F. C. Gomes, S. A. Haque, Q.-H. Liu, K. Mu, X. Xiong, M. E. Halloran, I. M. Longini Jr., S. Merler, M. Ajelli, A. Vespignani, Inferring high-resolution human mixing patterns for disease modeling. arXiv:2003.01214 [q-bio.PE] (25 February 2020).

25. K. Prem, A. R. Cook, M. Jit, Projecting social contact matrices in 152 countries using contact surveys and demographic data. PLOS Comput. Biol. 13, e1005697 (2017). doi:10.1371/journal.pcbi.1005697 Medline

26. K. Prem, Y. Liu, T. W. Russell, A. J. Kucharski, R. M. Eggo, N. Davies, M. Jit, P.
Klepac; Centre for the Mathematical Modelling of Infectious Diseases COVID-19 Working Group, The effect of control strategies to reduce social mixing on outcomes of the COVID-19 epidemic in Wuhan, China: A modelling study. Lancet Public Health S2468-2667(20)30073-6 (2020). doi:10.1016/S24682667(20)30073-6 Medline

27. D. L. Heymann, N. Shindo; WHO Scientific and Technical Advisory Group for Infectious Hazards, COVID-19: What is next for public health? Lancet 395, 542545 (2020). doi:10.1016/S0140-6736(20)30374-3 Medline

28. S. Riley, C. Fraser, C. A. Donnelly, A. C. Ghani, L. J. Abu-Raddad, A. J. Hedley, G. M. Leung, L. M. Ho, T. H. Lam, T. Q. Thach, P. Chau, K. P. Chan, S. V. Lo, P. Y. Leung, T. Tsang, W. Ho, K. H. Lee, E. M. Lau, N. M. Ferguson, R. M. Anderson, Transmission dynamics of the etiological agent of SARS in Hong Kong: Impact of public health interventions. Science 300, 1961-1966 (2003). doi:10.1126/science.1086478 Medline

29. J. Zhang, M. Litvinova, Y. Liang, Y. Wang, W. Wang, S. Zhao, Q. Wu, S. Merler, C. Viboud, A. Vespignani, M. Ajelli, H. Yu, Data and code for changes in contact patterns shape the dynamics of the novel coronavirus disease 2019 outbreak in China. Zenodo (2020); doi:10.5281/zenodo.3754583.

30. Ministry of Culture and Tourism of the People's Republic of China, Notice on extending the Spring Festival holiday of 2020 (2020); www.mct.gov.cn/whzx/whyw/202001/t20200127_850576.htm [accessed 11 March 2020].

31. Ministry of Culture and Tourism of the People's Republic of China, Notice on suspending group tours (2020): www.mct.gov.cn/whzx/ggtz/202001/t20200126 850571.htm [accessed 11 March 2020].

32. Ministry of Culture and Tourism of the People's Republic of China, Notice on the closure of public cultural services (2020); www.mct.gov.cn/whzx/whyw/202002/t20200204 850635.htm [accessed 11 March 2020].

33. L. Wang, B. J. Cowling, P. Wu, J. Yu, F. Li, L. Zeng, J. T. Wu, Z. Li, G. M. Leung, H. $\mathrm{Yu}$, Human exposure to live poultry and psychological and behavioral responses to influenza A(H7N9), China. Emerg. Infect. Dis. 20, 1296-1305 (2014). doi:10.3201/eid2008.131821 Medline

34. M. J. Keeling, P. Rohani, Modeling Infectious Diseases in Humans and Animals (Princeton Univ. Press, 2011), chap. 3

35. S. Lai, H. Zhou, W. Xiong, M. Gilbert, Z. Huang, J. Yu, W. Yin, L. Wang, Q. Chen, Y. Li, D. Mu, L. Zeng, X. Ren, M. Geng, Z. Zhang, B. Cui, T. Li, D. Wang, Z. Li, N. A. Wardrop, A. J. Tatem, H. Yu, Changing epidemiology of human brucellosis, China, 1955-2014. Emerg. Infect. Dis. 23, 184-194 (2017). doi:10.3201/eid2302.151710 Medline

36. S. Lai, N. W. Ruktanonchai, L. Zhou, O. Prosper, W. Luo, J. R. Floyd, A. Wesolowski, C. Zhang, X. Du, H. Yu, A. J. Tatem, Effect of non-pharmaceutical interventions for containing the COVID-19 outbreak: an observational and modelling study (2020); www.worldpop.org/events/COVID_NPI.

37. K. Leung, J. T. Wu, D. Liu, G. M. Leung, First-wave COVID-19 transmissibility and severity in China outside Hubei after control measures, and second-wave scenario planning: A modelling impact assessment. Lancet 395, 1382-1393 (2020). doi:10.1016/S0140-6736(20)30746-7 Medline

38. S. Muff, L. Held, L. Keller, Marginal or conditional regression models for correlated non-normal data? Methods Ecol. Evol. 7, 1514-1524 (2016). doi:10.1111/2041 210X.12623

39. A. Agresti, An Introduction to Categorical Data Analysis (Wiley, 2018).

40. R. Anderson, R. May, Infectious Diseases of Humans: Dynamics and Control (Oxford Univ. Press, 1991).

41. Q. H. Liu, M. Ajelli, A. Aleta, S. Merler, Y. Moreno, A. Vespignani, Measurability of the epidemic reproduction number in data-driven contact networks. Proc. Natl. Acad. Sci. U.S.A. 115, 12680-12685 (2018). doi:10.1073/pnas.1811115115 Medline

\section{ACKNOWLEDGMENTS}

The authors would like to acknowledge Benjamin J. Cowling from the University of Hong Kong and Christopher L. Gilbert from the Johns Hopkins University for their helpful comments on the manuscript and Nicole Samay for her assistance in preparing the figures. This article does not necessarily represent the views of the NIH or the US government. Funding: H.Y. acknowledges financial support 
from the National Science Fund for Distinguished Young Scholars (No. 81525023), Key Emergency Project of Shanghai Science and Technology Committee (No. 20411950100), National Science and Technology Major Project of China (No. 2018ZX10201001-010, No. 2018ZX10713001-007, No.

2017ZX10103009-005). The funder of the study had no role in study design,

data collection, data analysis, data interpretation, or writing of the report. S.M. and M.A. acknowledge financial support from the European Commission H2O2O MOOD project. Author contributions: M.A. and H.Y. are joint senior authors. H.Y. and M.A. designed the experiments. J.Z., Y.L., S.Z., and Q.W. collected data. J.Z., M.L., Y.W., W.W., Y.L., Q.W., and M.A. analyzed the data. J.Z., M.L., S.M., C.V., A.V., M.A., and H.Y. interpreted the results. J.Z., M.L. C.V., M.A., and H.Y. wrote the manuscript. A.V edited the manuscript. Competing interests: A.V. has received funding from Metabiota Inc. H.Y. has received research funding from Sanofi Pasteur, GlaxoSmithKline, Yichang HEC Changjiang Pharmaceutical Company, and Shanghai Roche Pharmaceutical Company. Ethics statement: Ethics approval was obtained from the institutional review board of the School of Public Health, Fudan University (IRB\#2020-01-0801). Verbal informed consent was obtained from all subjects (from a parent/guardian if participant was below 18 years of age). Data and materials availability: All data and code are available in the main text or the supplementary materials or in reference (29). This work is licensed under a Creative Commons Attribution 4.0 International (CC BY 4.0) license, which permits unrestricted use, distribution, and reproduction in any medium, provided the original work is properly cited. To view a copy of this license, visit https://creativecommons.org/licenses/by/4.0/. This license does not apply to figures/photos/artwork or other content included in the article that is credited to a third party; obtain authorization from the rights holder before using such material.

\section{SUPPLEMENTARY MATERIALS}

science.sciencemag.org/cgi/content/full/science.abb8001/DC1

Materials and Methods

Figs. S1 to S15

Tables S1 to S15

References (30-41)

MDAR Reproducibility Checklist

19 March 2020; accepted 27 April 2020

Published online 29 April 2020

10.1126/science.abb8001 
A
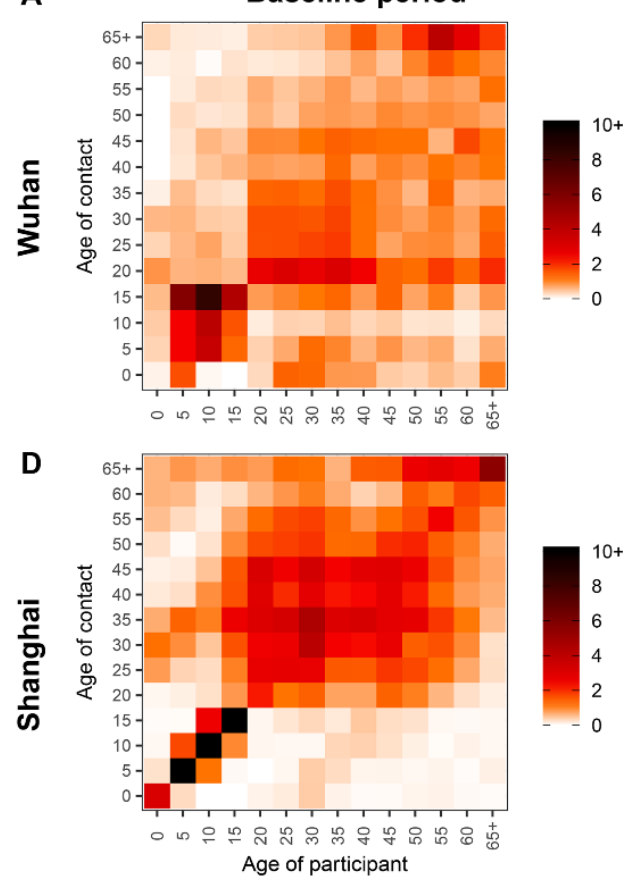

B
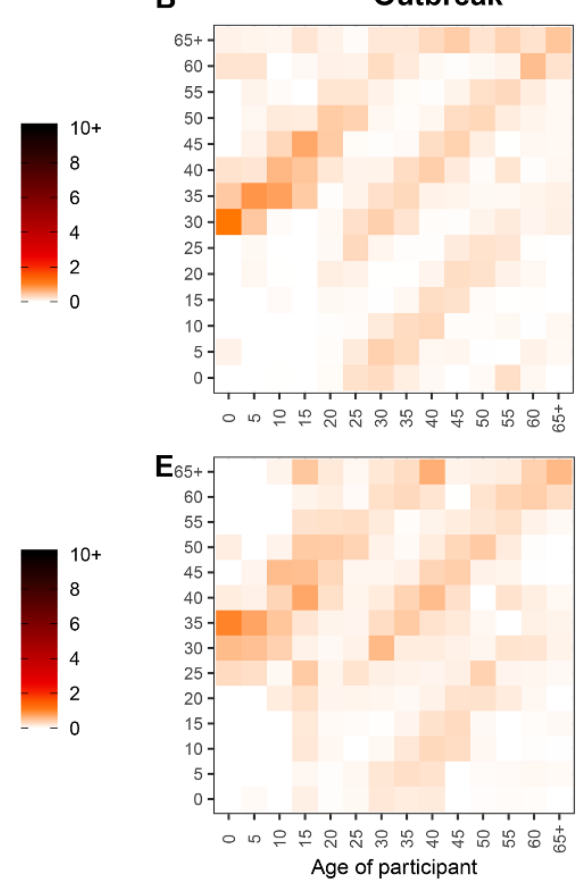

$E_{0}$

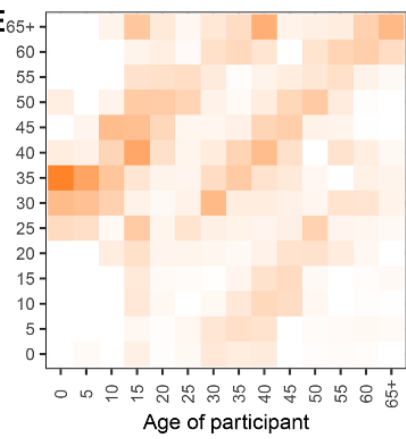

C
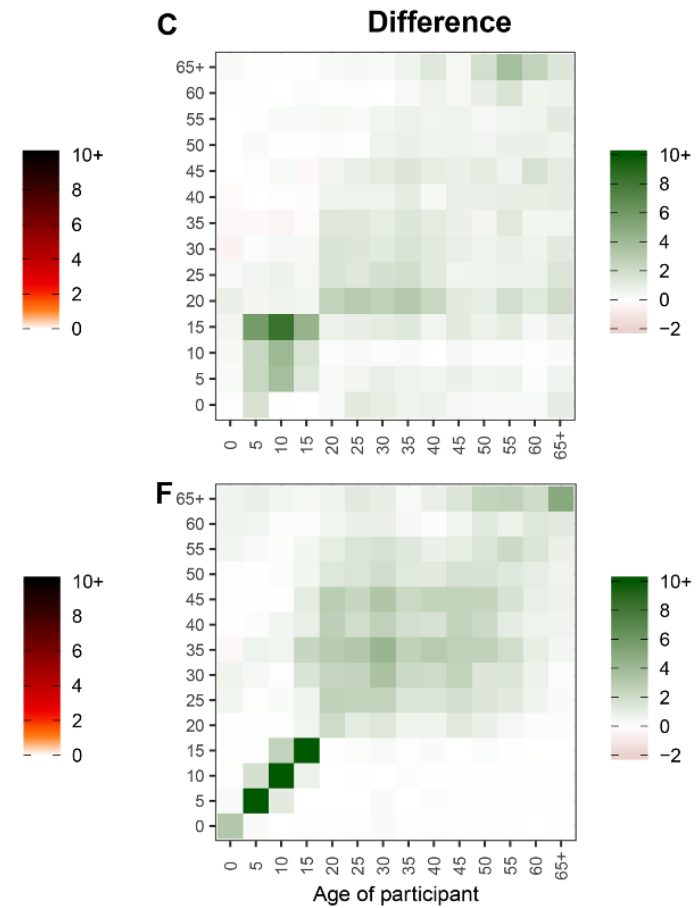

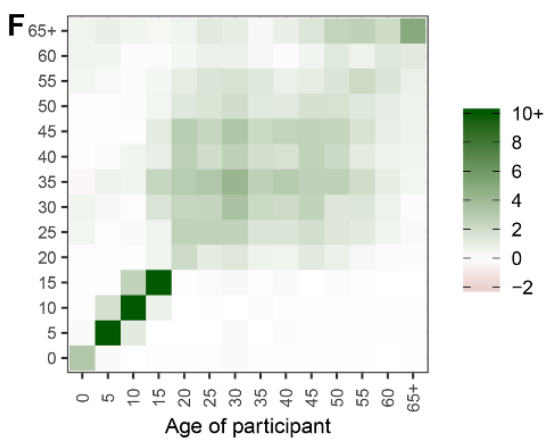

Fig. 1. Contact matrices by age. (A) Baseline period contact matrix for Wuhan (regular weekday only). Each cell of the matrix represents the mean number of contacts that an individual in a given age group has with other individuals, stratified by age groups. The color intensity represents the number of contacts. To construct the matrix we performed bootstrap sampling with replacement of survey participants weighted by the age distribution of the actual population of Wuhan. Every cell of the matrix represents an average over 100 bootstrapped realizations. (B) Same as (A), but for the outbreak contact matrix for Wuhan. (C) Difference between the baseline period contact matrix and the outbreak contact matrix in Wuhan. (D) Same as (A), but for Shanghai. (E and F) Same as (B) and (C), but for Shanghai. 

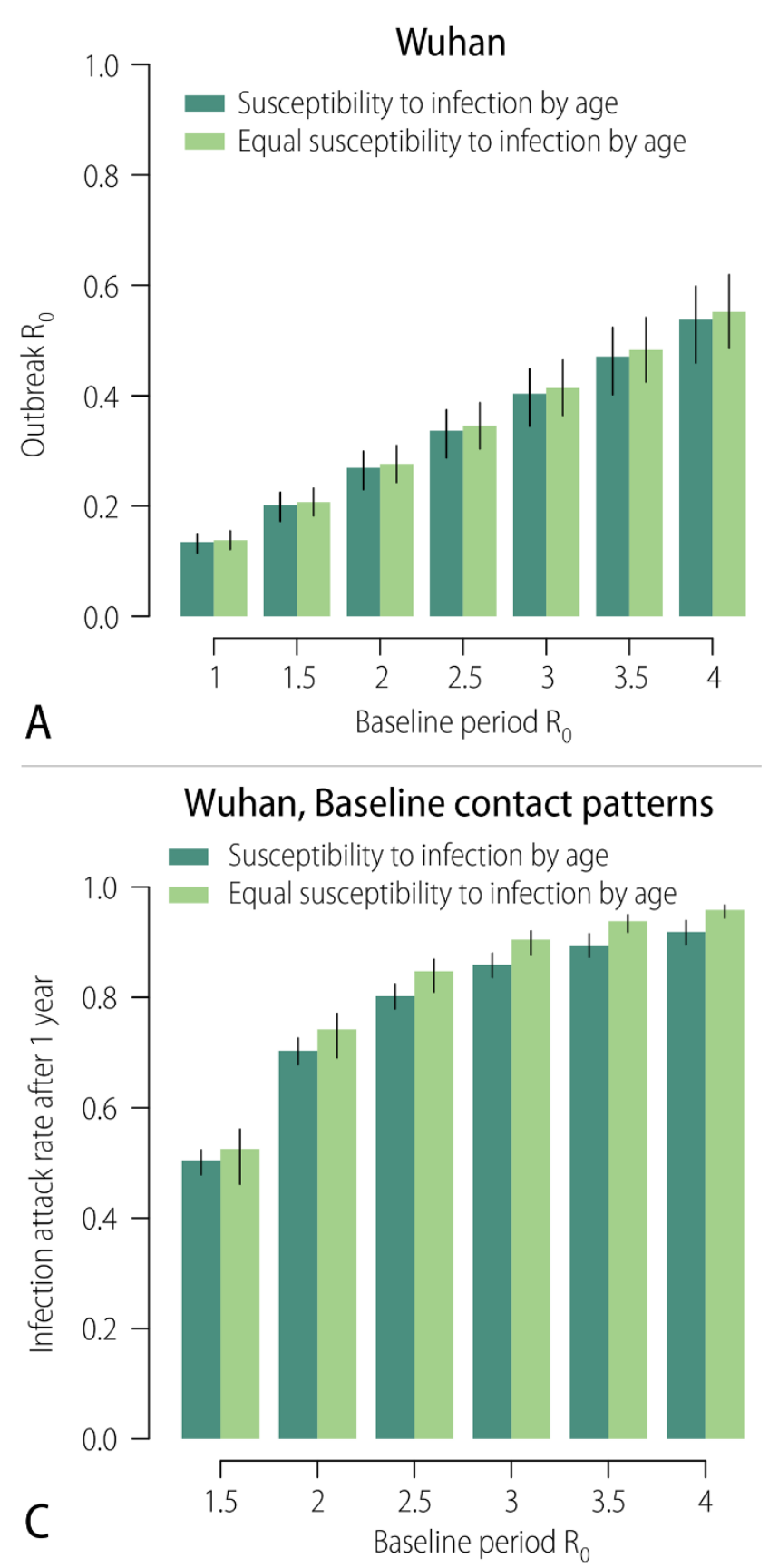
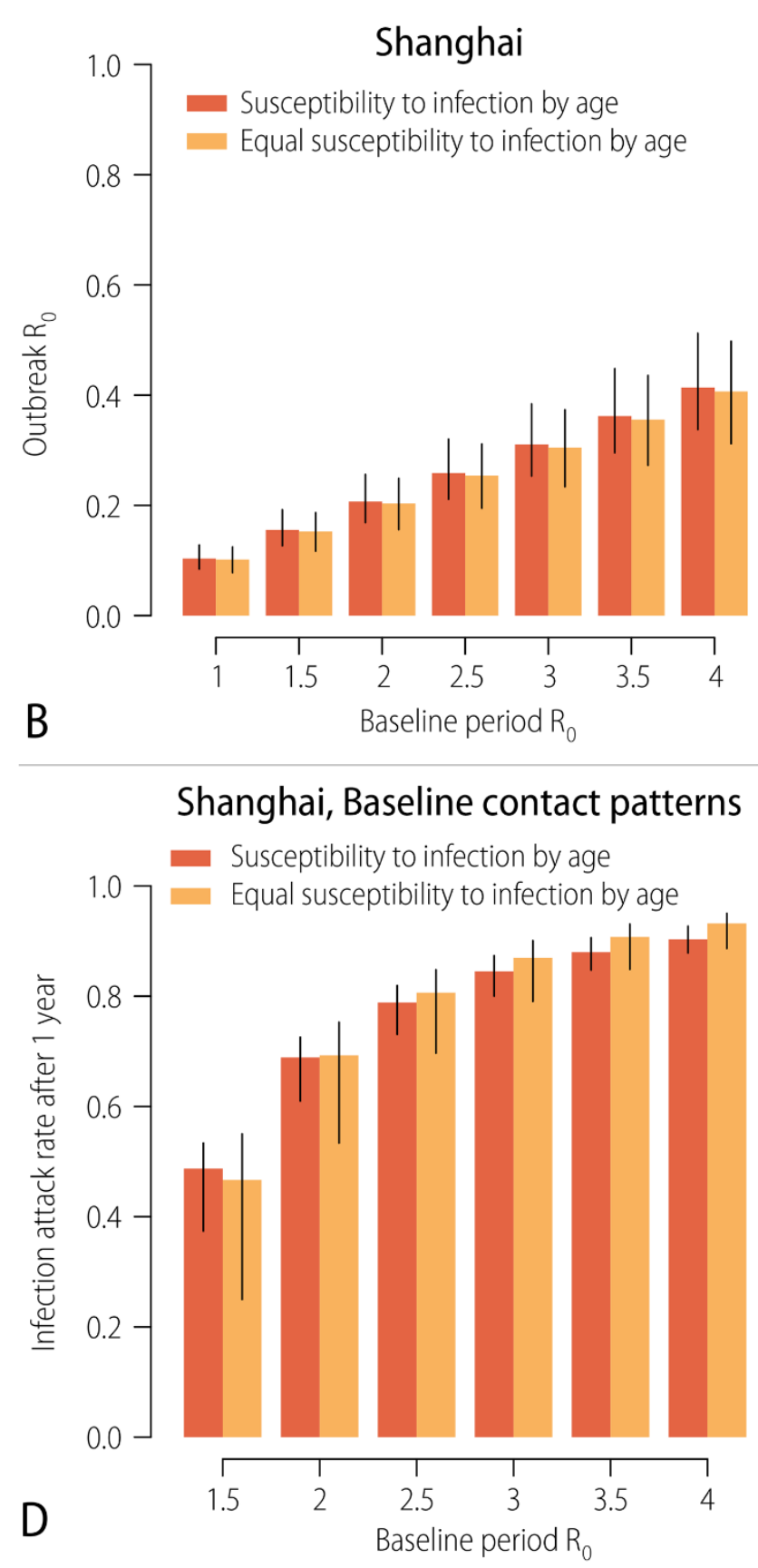

Fig. 2. Effect of contact patterns on the epidemic spread. (A) Estimated Ro during the outbreak (mean and $95 \% \mathrm{Cl}$ ), as a function of baseline $\mathrm{R}_{0}$ (i.e., that derived by using the contact matrix estimated for the baseline period). The figure refers to Wuhan and include both the scenario accounting for the estimated susceptibility to infection by age and assuming that all individuals are equally susceptible to infection. The distribution of the transmission rate is estimated through the next generation matrix approach by using 100 bootstrapped contact matrices for the baseline period in order to obtain the desired $R_{0}$ values. We then use the estimate distribution of the transmission rate the bootstrapped outbreak contact matrices to estimate $R_{0}$ for the outbreak period. The 95\% confidence intervals account for the uncertainty on the distribution of the transmission rate, mixing patterns, and susceptibility to infection by age. (B) As (A), but for Shanghai. (C) Infection attack rate one year after the initial case of COVID-19 (mean and 95\% $\mathrm{Cl}$ ) as a function of the baseline $\mathrm{R}_{0}$. The estimates are by simulating the SIR transmission model (see supplementary materials) using the contact matrix for the baseline period and considering the estimated susceptibility to infection by age and assuming that all individuals are equally susceptible to infection. The 95\% confidence intervals account for the uncertainty on the mixing patterns and susceptibility to infection by age. (D) As (C), but for Shanghai. 

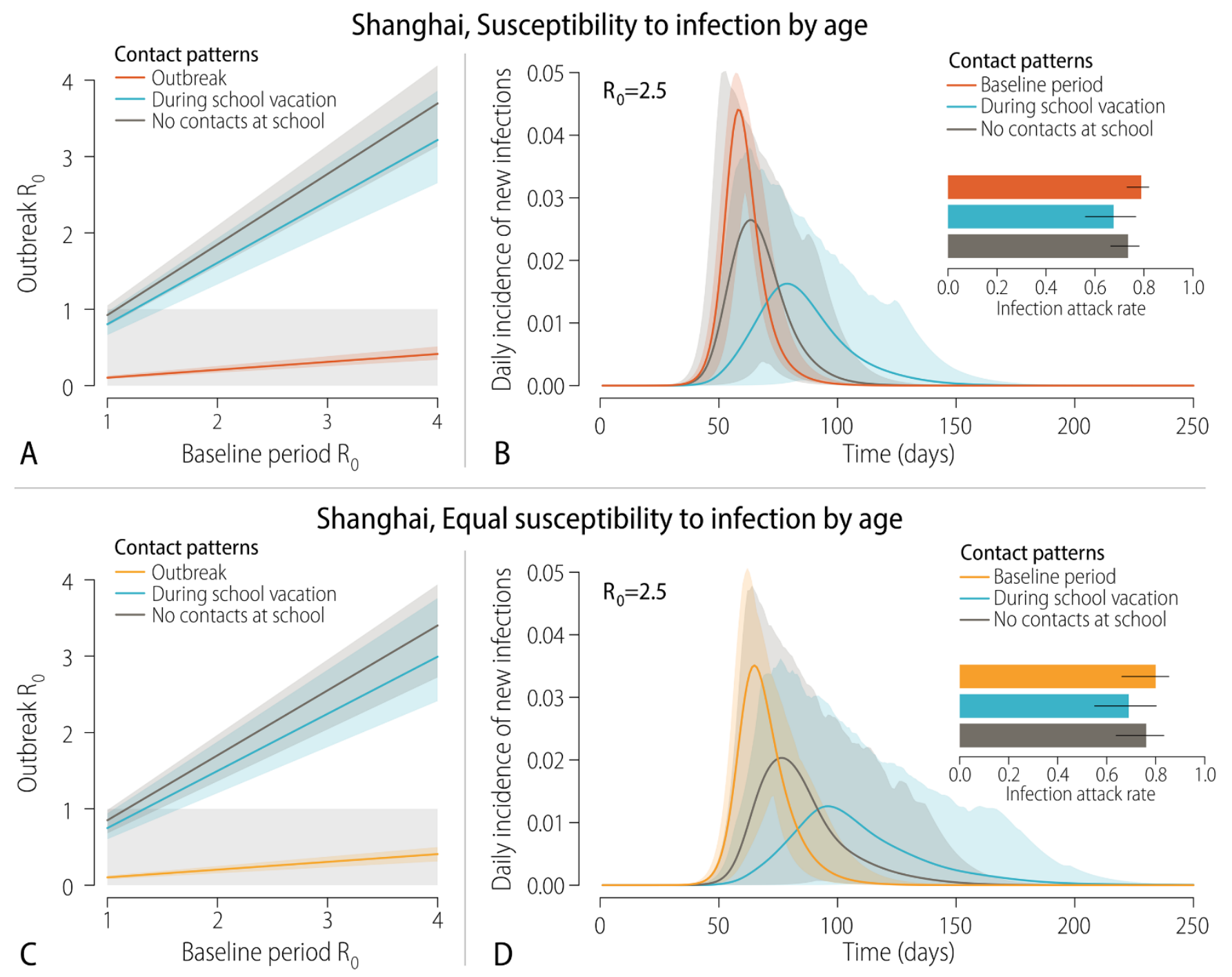

Fig. 3. Effect of limiting school contacts on the epidemic spread. (A) Estimated $R_{0}$ during the outbreak (mean and $95 \% \mathrm{Cl}$ ), as a function of baseline $\mathrm{R}_{0}$ (i.e., that derived by using the contact matrix estimated for the baseline period). The figure refers to Shanghai and the scenario accounting for the estimated susceptibility to infection by age. Three contact patterns are considered: i) as estimated during the COVID19 outbreak, ii) as estimated during school vacations (7) and iii) as estimated for the baseline period, but suppressing all contacts at school. (B) Daily incidence of new SARS-CoV-2 infections (mean and 95\% Cl) as estimated by the SIR model assuming age-specific susceptibility to infection (see supplementary materials). Three mixing patterns are considered: i) as estimated for the baseline period, ii) as estimated during school vacations (7) and iii) as estimated for the baseline period, but suppressing all contacts at school. The inset shows the infection attack rate one year after the introduction of the first COVID-19 case (mean and $95 \% \mathrm{Cl}$ ). (C) As (A), but assuming equal susceptibility to infection by age. (D) As (B), but assuming equal susceptibility to infection by age. 
Table 1. Number of contacts by demographic characteristics and location.

\begin{tabular}{|c|c|c|c|c|c|c|c|c|c|c|}
\hline \multirow{3}{*}{ Characteristics } & \multicolumn{5}{|c|}{ Wuhan } & \multicolumn{5}{|c|}{ Shanghai } \\
\hline & \multicolumn{2}{|c|}{ Baseline period } & \multicolumn{2}{|c|}{ COVID-19 Outbreak } & \multirow{2}{*}{ Difference $^{b}$} & \multicolumn{2}{|c|}{ Baseline period } & \multicolumn{2}{|c|}{ COVID-19 Outbreak } & \multirow{2}{*}{ Difference $^{b}$} \\
\hline & $\begin{array}{c}N \\
(\%)^{a}\end{array}$ & $\begin{array}{c}\text { Mean } \\
\left(95 \% \mathrm{Cl}^{\mathrm{c}}\right)\end{array}$ & $\begin{array}{c}N \\
(\%)^{a}\end{array}$ & $\begin{array}{c}\text { Mean } \\
\left(95 \% \mathrm{Cl}^{\mathrm{c}}\right)\end{array}$ & & $\begin{array}{c}N \\
(\%)\end{array}$ & $\begin{array}{c}\text { Mean } \\
\left(95 \% \mathrm{Cl}^{\mathrm{c}}\right)\end{array}$ & $\begin{array}{c}N \\
(\%)\end{array}$ & $\begin{array}{c}\text { Mean } \\
\left(95 \% \mathrm{Cl}^{\mathrm{c}}\right)\end{array}$ & \\
\hline Overall & $\begin{array}{c}624 \\
(100.0)\end{array}$ & $\begin{array}{c}14.6 \\
(12.9,16.3)\end{array}$ & $\begin{array}{c}627 \\
(100.0)\end{array}$ & $\begin{array}{c}2 \\
(1.9,2.1)\end{array}$ & $12.6 * * *$ & $\begin{array}{c}965 \\
(100.0)\end{array}$ & $\begin{array}{c}18.8 \\
(17.8,19.8)\end{array}$ & $\begin{array}{c}557 \\
(100.0)\end{array}$ & $\begin{array}{c}2.3 \\
(2,2.8)\end{array}$ & $16.4^{* * *}$ \\
\hline \multicolumn{11}{|l|}{ Sex } \\
\hline Male & $\begin{array}{c}300 \\
(48.1)\end{array}$ & $\begin{array}{c}14.5 \\
(12.2,17.1)\end{array}$ & $\begin{array}{l}301 \\
(48)\end{array}$ & $\begin{array}{c}1.8 \\
(1.7,2)\end{array}$ & $12.6 * * *$ & $\begin{array}{c}474 \\
(49.1)\end{array}$ & $\begin{array}{c}19 \\
(16.9,21)\end{array}$ & $\begin{array}{c}286 \\
(51.3)\end{array}$ & $\begin{array}{c}2.1 \\
(1.9,2.4)\end{array}$ & $16.9 * * *$ \\
\hline Female & $\begin{array}{c}324 \\
(51.9)\end{array}$ & $\begin{array}{c}14.7 \\
(12.5,17.1)\end{array}$ & $\begin{array}{l}326 \\
(52)\end{array}$ & $\begin{array}{c}2.1 \\
(2,2.3)\end{array}$ & $12.5^{* * *}$ & $\begin{array}{c}491 \\
(50.9)\end{array}$ & $\begin{array}{c}18.5 \\
(16.8,20.4)\end{array}$ & $\begin{array}{c}271 \\
(48.7)\end{array}$ & $\begin{array}{c}2.6 \\
(2.1,3.6)\end{array}$ & $16^{* * *}$ \\
\hline \multicolumn{11}{|l|}{ Age group } \\
\hline $0-6 y$ & $\begin{array}{c}12 \\
(1.9)\end{array}$ & $\begin{array}{c}8.6 \\
(3.4,17.4)\end{array}$ & $\begin{array}{c}12 \\
(1.9)\end{array}$ & $\begin{array}{c}2.2 \\
(1.7,2.8)\end{array}$ & $6.4^{* * *}$ & $\begin{array}{c}88 \\
(9.1)\end{array}$ & $\begin{array}{c}11.6 \\
(9.2,14.3)\end{array}$ & $\begin{array}{c}14 \\
(2.5)\end{array}$ & $\begin{array}{c}1.9 \\
(1.7,2.2)\end{array}$ & $9.7^{* * *}$ \\
\hline $7-19 y$ & $\begin{array}{c}79 \\
(12.7)\end{array}$ & $\begin{array}{c}16.2 \\
(12.7,19.6)\end{array}$ & $\begin{array}{c}79 \\
(12.6)\end{array}$ & $\begin{array}{c}2.1 \\
(2,2.2)\end{array}$ & $14.1^{* * *}$ & $\begin{array}{c}141 \\
(14.6)\end{array}$ & $\begin{array}{c}27 \\
(23.1,30.7)\end{array}$ & $\begin{array}{c}55 \\
(9.9)\end{array}$ & $\begin{array}{c}2.6 \\
(2,3.4)\end{array}$ & $24.5^{* * *}$ \\
\hline $20-39 y$ & $\begin{array}{c}254 \\
(40.7)\end{array}$ & $\begin{array}{c}15.3 \\
(12.8,18)\end{array}$ & $\begin{array}{c}256 \\
(40.8)\end{array}$ & $\begin{array}{c}2.1 \\
(1.9,2.2)\end{array}$ & $13.2^{* * *}$ & $\begin{array}{c}236 \\
(24.5)\end{array}$ & $\begin{array}{c}22.4 \\
(19.8,25.9)\end{array}$ & $\begin{array}{c}254 \\
(45.6)\end{array}$ & $\begin{array}{c}2.2 \\
(2,2.5)\end{array}$ & $20.2^{* * *}$ \\
\hline
\end{tabular}




\begin{tabular}{|c|c|c|c|c|c|c|c|c|c|c|}
\hline \multirow{3}{*}{ Characteristics } & \multicolumn{5}{|c|}{ Wuhan } & \multicolumn{5}{|c|}{ Shanghai } \\
\hline & \multicolumn{2}{|c|}{ Baseline period } & \multicolumn{2}{|c|}{ COVID-19 Outbreak } & \multirow{2}{*}{ Difference $^{b}$} & \multicolumn{2}{|c|}{ Baseline period } & \multicolumn{2}{|c|}{ COVID-19 Outbreak } & \multirow{2}{*}{ Difference } \\
\hline & $\begin{array}{c}N \\
(\%)^{a}\end{array}$ & $\begin{array}{c}\text { Mean } \\
\left(95 \% \mathrm{Cl}^{\mathrm{c}}\right)\end{array}$ & $\begin{array}{c}N \\
(\%)^{\mathrm{a}}\end{array}$ & $\begin{array}{c}\text { Mean } \\
\left(95 \% \mathrm{Cl}^{\mathrm{c}}\right)\end{array}$ & & $\begin{array}{c}\mathrm{N} \\
(\%)\end{array}$ & $\begin{array}{c}\text { Mean } \\
\left(95 \% \mathrm{Cl}^{\mathrm{c}}\right)\end{array}$ & $\begin{array}{c}\mathrm{N} \\
(\%)\end{array}$ & $\begin{array}{c}\text { Mean } \\
\left(95 \% \mathrm{Cl}^{\mathrm{c}}\right)\end{array}$ & \\
\hline $40-59 y$ & $\begin{array}{c}221 \\
(35.4)\end{array}$ & $\begin{array}{c}13.8 \\
(11.4,16.7)\end{array}$ & $\begin{array}{c}220 \\
(35.1)\end{array}$ & $\begin{array}{c}2 \\
(1.8,2.2)\end{array}$ & $11.8^{* * *}$ & $\begin{array}{c}233 \\
(24.1)\end{array}$ & $\begin{array}{c}19.9 \\
(17.7,23.3)\end{array}$ & $\begin{array}{c}160 \\
(28.7)\end{array}$ & $\begin{array}{c}2.8 \\
(2,4.1)\end{array}$ & $17.1^{* * *}$ \\
\hline$\geq 60 \mathrm{y}$ & $\begin{array}{c}58 \\
(9.3)\end{array}$ & $\begin{array}{c}13.9 \\
(7.9,20.7)\end{array}$ & $\begin{array}{c}60 \\
(9.6)\end{array}$ & $\begin{array}{c}1.4 \\
(1.2,1.7)\end{array}$ & $11.6^{* * *}$ & $\begin{array}{c}267 \\
(27.7)\end{array}$ & $\begin{array}{c}12.6 \\
(10.8,14.7)\end{array}$ & $\begin{array}{c}74 \\
(13.3)\end{array}$ & $\begin{array}{c}1.6 \\
(1.3,1.8)\end{array}$ & $11^{* * *}$ \\
\hline \multicolumn{11}{|c|}{ Type of profession } \\
\hline Pre-school & $\begin{array}{c}12 \\
(1.9)\end{array}$ & $\begin{array}{c}8.6 \\
(3.4,17.4)\end{array}$ & $\begin{array}{c}12 \\
(1.9)\end{array}$ & $\begin{array}{c}2.2 \\
(1.7,2.8)\end{array}$ & $6.4^{* * *}$ & $\begin{array}{c}79 \\
(8.2)\end{array}$ & $\begin{array}{c}10.4 \\
(8,13.3)\end{array}$ & $\begin{array}{c}14 \\
(2.5)\end{array}$ & $\begin{array}{c}1.9 \\
(1.7,2.1)\end{array}$ & $8.5^{* * *}$ \\
\hline Student & $\begin{array}{c}107 \\
(17.1)\end{array}$ & $\begin{array}{c}14.6 \\
(11.4,18.2)\end{array}$ & $\begin{array}{c}107 \\
(17.1)\end{array}$ & $\begin{array}{c}2.1 \\
(2,2.3)\end{array}$ & $12.5^{* * *}$ & $\begin{array}{c}173 \\
(17.9)\end{array}$ & $\begin{array}{c}26.2 \\
(23.1,29.2)\end{array}$ & $\begin{array}{c}71 \\
(12.7)\end{array}$ & $\begin{array}{c}2.5 \\
(2,3.4)\end{array}$ & $23.7^{* * *}$ \\
\hline Employed & $\begin{array}{c}391 \\
(62.7)\end{array}$ & $\begin{array}{c}15.4 \\
(13.4,17.4)\end{array}$ & $\begin{array}{c}390 \\
(62.2)\end{array}$ & $\begin{array}{c}2.1 \\
(1.9,2.2)\end{array}$ & $13.2^{* * *}$ & $\begin{array}{c}400 \\
(41.5)\end{array}$ & $\begin{array}{c}22.5 \\
(20.7,24.4)\end{array}$ & $\begin{array}{c}354 \\
(63.6)\end{array}$ & $\begin{array}{c}2.5 \\
(2.1,3.2)\end{array}$ & $20 * * *$ \\
\hline Unemployed & $\begin{array}{c}30 \\
(4.8)\end{array}$ & $\begin{array}{c}14.1 \\
(5.7,24.2)\end{array}$ & $\begin{array}{c}31 \\
(4.9)\end{array}$ & $\begin{array}{c}1.8 \\
(1.4,2.4)\end{array}$ & $12.2^{* * *}$ & $\begin{array}{l}29 \\
(3)\end{array}$ & $\begin{array}{c}14.5 \\
(7.8,24.2)\end{array}$ & $\begin{array}{c}24 \\
(4.3)\end{array}$ & $\begin{array}{c}1.8 \\
(1.3,2.4)\end{array}$ & $12.6^{* * *}$ \\
\hline Retired & $\begin{array}{c}84 \\
(13.5)\end{array}$ & $\begin{array}{c}12.1 \\
(7.2,17.4)\end{array}$ & $\begin{array}{c}87 \\
(13.9)\end{array}$ & $\begin{array}{c}1.5 \\
(1.3,1.7)\end{array}$ & $10.6^{* * *}$ & $\begin{array}{c}278 \\
(28.8)\end{array}$ & $\begin{array}{c}11.8 \\
(10.2,13.2)\end{array}$ & $\begin{array}{c}94 \\
(16.9)\end{array}$ & $\begin{array}{c}1.6 \\
(1.3,1.8)\end{array}$ & $10.2^{* * *}$ \\
\hline
\end{tabular}




\begin{tabular}{|c|c|c|c|c|c|c|c|c|c|c|}
\hline \multirow{3}{*}{ Characteristics } & \multicolumn{5}{|c|}{ Wuhan } & \multicolumn{5}{|c|}{ Shanghai } \\
\hline & \multicolumn{2}{|c|}{ Baseline period } & \multicolumn{2}{|c|}{ COVID-19 Outbreak } & \multirow{2}{*}{ Difference $^{b}$} & \multicolumn{2}{|c|}{ Baseline period } & \multicolumn{2}{|c|}{ COVID-19 Outbreak } & \multirow{2}{*}{ Difference $^{\mathrm{b}}$} \\
\hline & $\begin{array}{c}N \\
(\%)^{a}\end{array}$ & $\begin{array}{c}\text { Mean } \\
\left(95 \% \mathrm{Cl}^{\mathrm{c}}\right)\end{array}$ & $\begin{array}{c}N \\
(\%)^{\mathrm{a}}\end{array}$ & $\begin{array}{c}\text { Mean } \\
\left(95 \% \mathrm{Cl}^{\mathrm{c}}\right)\end{array}$ & & $\begin{array}{c}\mathrm{N} \\
(\%)\end{array}$ & $\begin{array}{c}\text { Mean } \\
\left(95 \% \mathrm{Cl}^{\mathrm{c}}\right)\end{array}$ & $\begin{array}{c}N \\
(\%)\end{array}$ & $\begin{array}{c}\text { Mean } \\
\left(95 \% \mathrm{Cl}^{\mathrm{c}}\right)\end{array}$ & \\
\hline \multicolumn{11}{|l|}{ Household size } \\
\hline 1 & $\begin{array}{c}45 \\
(7.2)\end{array}$ & $\begin{array}{c}10.5 \\
(5.3,17.2)\end{array}$ & $\begin{array}{c}45 \\
(7.2)\end{array}$ & $\begin{array}{c}0.6 \\
(0.1,1.5)\end{array}$ & $9.9 * * *$ & $\begin{array}{c}35 \\
(3.6)\end{array}$ & $\begin{array}{c}15.2 \\
(10.1,21.1)\end{array}$ & $\begin{array}{c}61 \\
(11)\end{array}$ & $\begin{array}{c}0.3 \\
(0.1,0.5)\end{array}$ & $14.9 * * *$ \\
\hline 2 & $\begin{array}{c}73 \\
(11.7)\end{array}$ & $\begin{array}{c}12.6 \\
(8.2,18.3)\end{array}$ & $\begin{array}{c}76 \\
(12.1)\end{array}$ & $\begin{array}{c}1.1 \\
(1,1.2)\end{array}$ & $11.5^{* * *}$ & $\begin{array}{c}244 \\
(25.3)\end{array}$ & $\begin{array}{c}14.5 \\
(12.7,16.7)\end{array}$ & $\begin{array}{c}138 \\
(24.8)\end{array}$ & $\begin{array}{c}1.4 \\
(1.1,1.7)\end{array}$ & $13.1^{* * *}$ \\
\hline 3 & $\begin{array}{c}282 \\
(45.2)\end{array}$ & $\begin{array}{c}14.8 \\
(12.8,17.3)\end{array}$ & $\begin{array}{c}283 \\
(45.1)\end{array}$ & $\begin{array}{c}1.9 \\
(1.8,2)\end{array}$ & $13^{* * *}$ & $\begin{array}{c}432 \\
(44.8)\end{array}$ & $\begin{array}{c}20.3 \\
(17.7,22.4)\end{array}$ & $\begin{array}{c}216 \\
(38.8)\end{array}$ & $\begin{array}{c}2.2 \\
(2,2.3)\end{array}$ & $18.1^{* * *}$ \\
\hline 4 & $\begin{array}{c}133 \\
(21.3)\end{array}$ & $\begin{array}{c}11.9 \\
(9.3,15)\end{array}$ & $\begin{array}{c}132 \\
(21.1)\end{array}$ & $\begin{array}{c}2.3 \\
(2.2,2.5)\end{array}$ & $9.6^{* * *}$ & $\begin{array}{c}117 \\
(12.1)\end{array}$ & $\begin{array}{c}20.3 \\
(16.5,23.8)\end{array}$ & $\begin{array}{l}78 \\
(14)\end{array}$ & $\begin{array}{c}3 \\
(2.8,3.3)\end{array}$ & $17.3^{* * *}$ \\
\hline$\geq 5$ & $\begin{array}{c}91 \\
(14.6)\end{array}$ & $\begin{array}{c}21.5 \\
(16.2,27.3)\end{array}$ & $\begin{array}{c}91 \\
(14.5)\end{array}$ & $\begin{array}{c}3.2 \\
(2.9,3.4)\end{array}$ & $17.8^{* * *}$ & $\begin{array}{c}137 \\
(14.2)\end{array}$ & $\begin{array}{c}21.4 \\
(18.2,27)\end{array}$ & $\begin{array}{c}64 \\
(11.5)\end{array}$ & $\begin{array}{c}5.9 \\
(4,9.9)\end{array}$ & $15.5^{* * *}$ \\
\hline
\end{tabular}

aCan differ from total sample size $(n=636)$ as it also includes participants who had not recorded contacts during the baseline period or during the COVID-19 outbreak. Note that reduced denominators indicate missing data. Percentages may not total 100 because of rounding.

${ }^{b}$ Difference is calculated by the subtraction of the number of contacts during the outbreak from the number of contacts during the baseline period. P-values are taken from a negative binomial regression with a single binary variable distinguishing the baseline period from the outbreak.

'The 95\% confidence interval on the mean are calculated by bootstrap sampling.

${ }^{*} p<0.05,{ }^{* *} p<0.01,{ }^{* *} p<0.001$. 